\title{
Characteristics of contrast-enhanced ultrasonography and strain elastography of locally advanced breast cancer
}

\author{
Li-Shuang Gu ${ }^{2 \#}$, Rui Zhang ${ }^{1 \#}$, Yong Wang ${ }^{1}$, Xue-Mei Liu ${ }^{2}$, Fei Ma ${ }^{3}$, Jia-Yu Wang ${ }^{3}$, Xiao-Ying Sun ${ }^{4}$, \\ Meng-Jia Liu ${ }^{1}$, Bo Wang ${ }^{1}$, Shuang-Mei Zou ${ }^{5}$
}

${ }^{1}$ Department of Ultrasound, National Cancer Center/National Clinical Research Center for Cancer/Cancer Hospital, Chinese Academy of Medical Sciences and Peking Union Medical College, Beijing 100021, China; ${ }^{2}$ Department of Ultrasound, Beijing Hospital of Traditional Chinese Medicine, Capital Medical University, Beijing 100010, China; ${ }^{3}$ Department of Breast Diseases, National Cancer Center/National Clinical Research Center for Cancer/Cancer Hospital, Chinese Academy of Medical Sciences and Peking Union Medical College, Beijing 100021 , China; ${ }^{4}$ Department of Medical Oncology, Cancer Hospital of Huanxing Chaoyang District, Beijing 100122, China; ${ }^{5}$ Department of Pathology, National Cancer Center/National Clinical Research Center for Cancer/Cancer Hospital, Chinese Academy of Medical Sciences and Peking Union Medical College, Beijing 100021, China

Contributions: (I) Conception and design: LS Gu, Y Wang, R Zhang, XM Liu; (II) Administrative support: Y Wang, F Ma, JY Wang; (III) Provision of study materials or patients: Y Wang, F Ma, JY Wang, XY Sun, SM Zou; (IV) Collection and assembly of data: LS Gu, R Zhang, XM Liu, MJ Liu, B Wang; (V) Data analysis and interpretation: LS Gu, Y Wang; (VI) Manuscript writing: All authors; (VII) Final approval of manuscript: All authors.

\#These authors contributed equally to this work.

Correspondence to: Yong Wang. Department of Ultrasound, National Cancer Center/National Clinical Research Center for Cancer/Cancer Hospital, Chinese Academy of Medical Sciences and Peking Union Medical College, Panjiayuannanli No. 17, Chaoyang District, Beijing 100021, China. Email: drwangyong77@163.com; Xue-Mei Liu. Department of Ultrasound, Beijing Hospital of Traditional Chinese Medicine, Capital Medical University, No. 23, Art Museum Back Street Dongcheng District, Beijing 100010, China. Email: kaidongliu102@sina.com.

Background: Locally advanced breast cancer (LABC) is one of the subgroups of invasive breast cancer. The treatment of LABC is neoadjuvant chemotherapy (NAC) before surgery, which is different from the others. The study aimed to analyze and compare the characteristics of conventional ultrasound, contrastenhanced ultrasonography (CEUS) and strain elastography (SE) in LABC patients who have different treatment outcomes, and to provide help for LABC in the imaging diagnosis and clinic treatment.

Methods: From May 2018 to April 2019, 36 patients (40 lesions) of LABC were enrolled, which diagnosed by puncture biopsy. According to the clinical evaluation, these patients were recommended to undergo preoperative NAC followed by surgery. All patients underwent conventional ultrasound, CEUS and SE before puncture. According to postoperative pathological grading and follow-up, the patients were divided into effective and ineffective groups. We summarized and compared the features of conventional ultrasound, CEUS and SE of patients in two groups. The correlation between the imaging characteristics and the postoperative pathological grading was also analyzed.

Results: Conventional ultrasonic features of LABC: the most lesions of LABC were mass type (32/40, $80.0 \%)$, and all lesions were irregular. Most of lesions showed unclear boundaries (39/40, 97.5\%), heterogeneous echoes (38/40, 95.0\%), and internal calcifications (24/40, 60.0\%). Most of lesions had hyperechoic halos $(31 / 40,77.5 \%)$, aspect ratio less than or equal to $1(34 / 40,85.0 \%)$, and blood flow grading was III (36/40, 90.0\%). CEUS features of LABC: compared with the surrounding normal tissues, all the lesions (40/40,100.0\%) were highly enhanced. Most of lesions (35/40, 87.5\%) were uneven enhanced. The main enhancement mode was "fast in and slow out" (39/40, 97.5\%). There were totally 25 lesions which had "solar sign" (25/40, 62.5\%). SE features of LABC: the average visual elastography score of the lesions was $4.28 \pm 0.67$, the maximum strain rate (E1) of the lesions averaged $4.88 \pm 0.54$, and the overall strain rate of the lesion averaged $4.14 \pm 0.72$. There was no significant difference between effective and ineffective groups in the characteristics of conventional ultrasound, CEUS and SE. There was a correlation between the appearance of "solar sign" in CEUS and postoperative pathological grading, and the contingency coefficient was 0.564 
$(\mathrm{P}<0.05)$. The pathological grading of patients without solar sign was higher. The other characteristics of conventional ultrasound, CEUS and SE in LABC patients had no correlation with postoperative pathological grading.

Conclusions: In LABC, the conventional ultrasound usually shows irregular shape and unclear boundaries. The aspect ratio is less than or equal to 1. CEUS showed uneven enhancement of "fast in and slow out", and "solar sign" was often seen. Elastography showed that the texture of the lesion was significantly stiffer than the surrounding normal tissue. Ultrasound imaging before NAC had no relationship with pathological complete response or not. However, "solar sign" in CEUS was an important feature and had correlation with postoperative pathological grading.

Keywords: Breast cancer; conventional ultrasound; contrast-enhanced ultrasonography (CEUS); strain elastography

Submitted Sep 10, 2019. Accepted for publication Nov 20, 2019.

doi: $10.21037 /$ jtd.2019.11.52

View this article at: http://dx.doi.org/10.21037/jtd.2019.11.52

\section{Introduction}

Breast cancer is one of the most common malignant tumors in the world, which seriously endangers women's health. It accounts for about $7-10 \%$ of all kinds of malignant tumors in women, and its incidence is still on the rise (1). Locally advanced breast cancer (LABC) is one of the subgroups of invasive breast cancer. Tumor cells of LABC limit to lymph nodes in the breast and drainage area and cannot be completely removed, or lesions cannot be guaranteed to have negative cutting margins after breastconserving surgery. The treatment is mainly neoadjuvant chemotherapy (NAC) followed by surgical treatment $(2,3)$. Therefore, accurate diagnosis of LABC is very important for the establishment of treatment. For patients of LABC, the effectiveness of NAC also affects the choice of follow-up treatment. Therefore, imaging diagnosis and evaluation of LABC are very important. Imaging diagnosis and evaluation methods of breast lesions include computed tomography (CT), magnetic resonance imaging (MRI), PET-CT and conventional ultrasound (4). Diagnostic efficiency of CT is not as good as MRI besides its radioactivity. MRI is a functional imaging with high diagnostic accuracy (5), but it has the disadvantage of being time-consuming. Its price is also expensive. Patients with claustrophobia and heart metal stent cannot be examined (6,7). PET-CT has high diagnostic accuracy (8), but it is very expensive so that not all patients accept it.

Contrast-enhanced ultrasonography (CEUS) and strain elastography (SE), as the ultrasound multi-mode imaging methods, not only present the size, boundary, shape and the other characteristics of lesions, but also clearly show the blood perfusion both inside and around the tumor (9). They could provide important help for clinical diagnosis. SE mainly reflects hardness of tissue. It can not only provide the changes of hardness in vision, but also provide quantitative strain rate value $(10,11)$. However, at present, the benign and malignant diagnosis of breast tumors with CEUS and SE is only reported in some literatures $(12,13)$. Clinical applications are rare. In summary, this study aims to analyze and compare the characteristics and quantitative parameters of conventional ultrasound, CEUS and SE in LABC patients, and to provide help for LABC in the imaging diagnosis and clinic treatment.

\section{Methods}

\section{Patients' selection}

Thirty-six cases (40 lesions) of LABC confirmed by clinical evaluation and puncture biopsy in National Cancer Center/ Cancer Hospital, Chinese Academy of Medical Sciences and Peking Union Medical College from May 2018 to April 2019 were collected. All patients accepted conventional ultrasound, CEUS and SE examination before puncture.

\section{Inclusion criteria}

(I) Patients who signed the informed consent for CEUS and elastography;

(II) Patients with breast cancer confirmed by puncture biopsy and LABC confirmed by clinical and imaging evaluation. 


\section{Exclusion criteria}

(I) Patients with severe skin ulceration that caused by local invasion of tumor and unable to conduct contact examination;

(II) Patients with severe cardiopulmonary, hepatic or renal insufficiency and mental abnormality who could not cooperate with the examination.

\section{Imaging technique and interpretation}

\section{Conventional ultrasound}

Breast conventional ultrasound was performed by using the scanners of LOGIQ E9 (GE Healthcare, Milwaukee, WI, USA) with the 6-8 MHz linear transducer and a 3-5 MHz curve transducer. Ask the patients to take the supine position so as to fully expose the breast. Conduct a comprehensive scan of bilateral breast and axilla. After the suspicious lesions were found, multi-section and multi-angle scanning were performed on the lesions. The conventional ultrasound characteristics of the lesions were recorded, TD, APD, ULD, circumference and area of the maximum transverse section were also recorded. In the cases of multiple lesions, the features of the two largest lesions were recorded. Meanwhile, color Doppler flow imaging (CDFI) was used to observe the blood Flow. According to the Adler classification, the tumor blood flow signals were divided into 4 grades: grade 0 presents no blood flow signals; grade 1 presents the spot or short line blood flow in the lesions; grade 2 refers to 3-4 punctate or short-line blood flow signals in the lesions, or one blood flow of which length is greater or equal to the radius of the lesions; In grade 3 , more than three stripe blood vessels are found in the lesions, which form a network (14). Meanwhile, the blood flow resistance index (RI) was measured and recorded.

\section{SE}

The maximum cross sections of lesions were selected. If it was non-mass lesions in the conventional ultrasound, the maximum cross sections of diffuse calcification or echo-disordered areas were selected. The sampling boxes were selected to include the lesions and surrounding normal tissues. The probe was kept perpendicular to the lesions and slightly compressed to make a tiny vibration. When the color frame was green and full, it indicated that pressure curve was relatively stable (indicating that the pressure was appropriate). Obtain a relatively stable elastic image and observe the color of the lesions. Tsukuba elasticity score (TES) was used for scoring according to different colors (15). The hardness increases gradually from green to blue. The images showed that the lesions were rated as 1 point in green; lesions with mixed blue-green were rated as 2 points; it was rated as 3 points when lesions had the blue center; it was rated as 4 points when the whole lesions were blue; the lesions and surrounding tissues all in blue were rated as 5 points. After scoring, the measurement software of strain rate ratio of elastography was used. The area with the deepest blue ( $5 \mathrm{~mm}$ highest hardness area) was taken as the region of interest (ROI), and the strain value of it was measured. The average E1 of lesions was measured for 5 times. The strain value of normal tissues in the same size and level was measured for 5 times as E2. The value of E1/ $\mathrm{E} 2$ was recorded at the same time. The Em was value of the overall average strain rate. The larger the displayed value, the higher the hardness of the mass.

\section{CEUS}

Breast CEUS examination was performed by the scanners of LOGIQ E9 (GE Healthcare, Milwaukee, WI, USA) with a $6-8 \mathrm{MHz}$ linear transducer. The maximum cross sections of the lesions were selected for observation. If the conventional ultrasound presented non-mass lesion, the transverse section with the largest diffuse calcification or echo-disordered area was selected. After the conventional ultrasound images of lesions were clear, the dual-screen CEUS mode was switched. The mechanical index was fixed at 0.06 , and the focus was placed at the bottom of the image. SonoVue (Italy, Bracco) was selected as the contrast agent. Add $5 \mathrm{ml}$ normal saline into the freeze-dried powder and shake it adequately to ensure sufficient dispersion of microbubbles. After $5 \mathrm{~mL}$ of SonoVue agent was injected into the patient's median cubital vein, $5 \mathrm{~mL}$ of normal saline was used to flush the tube. Dynamic storage and timer were started at the same time. The storage time was $3 \mathrm{~min}$. Two ultrasound doctors experienced in breast CEUS performed frame-by-frame playback analysis of the CEUS images. Observe and record the CEUS characteristics of the lesions. The recorded features included enhancement patterns: fast in, slow in, fast out or slow out, which were compared with the time of normal breast tissues enhancement. Enhancement intensity: high enhancement, equal enhancement, low enhancement or no enhancement, all compared with enhancement intensity of normal breast tissue at the same level; the texture of enhancement: homogeneous, heterogeneous; boundary: clear, unclear; shape: regular, irregular; whether there is "solar sign" (large 
radial blood vessels that radiated from the periphery into the tumors); whether lesions invaded the skin, muscles, nipples. Measure and record TD, APD, perimeter, and area of the lesions. Select ROI with the diameter of $5 \mathrm{~mm}$, draw the time-intensity curve (TIC) and record AT, TTP, PI, k and AUC of lesions.

\section{Pathological and clinical evaluation}

All the enrolled patients underwent puncture biopsy and immunohistochemical examination, which confirmed breast cancer or lymph node metastasis in the drainage area. After clinical and imaging staging evaluation of lesions, NAC was conducted according to AJCC standard (16). The patients underwent surgery after NAC were graded by pathological according to Miller-Payne criterion (17). The efficacy of NAC was divided into 5 levels: G1: some cancer cells changed, but the total number did not decrease. G2: cancer cells had a reduction rate of $<30 \%$, but the total number was still high. G3: moderate decrease in cancer cells, $\geq 30 \%$ but $<90 \%$. G4: cancer cells were significantly reduced by $\geq$ $90 \%$, and only scattered cell clusters were seen.G5: no cancer cells in the original tumor site.G1, G2 and G3 were classified as ineffective group.G4 and G5 were classified as effective group. Patients with distant metastasis after four cycles of NAC treatment were also classified as ineffective.

\section{Statistical analysis}

SPSS20.0 statistical software was used for statistical analysis. Counting data were expressed as percentage (\%), and measurement data were expressed as mean \pm standard deviation. Chi-square test was used for qualitative data between the effective group and ineffective group, and $t$-test was used for quantitative data between the effective group and ineffective group. Spearman rank correlation was used between measurement data and rank data. Contingency table of correlation analysis was used between the counting data and the rank data. Record the correlation coefficient and $P$ value. $P<0.05$ was statistically significant.

\section{Results}

\section{Clinical data}

In this study, a total of 36 patients (40 lesions) confirmed LABC were included. All patients were female, presented with breast masses. The average course of disease was
2-24 months. The clinical stage was IIa-IIIc. Thirtyfour cases (38 lesions) infiltrating ductal carcinoma and 2 cases (2 lesions) infiltrating micropapillary carcinoma were confirmed by coarse needle puncture biopsy and postoperative pathology. Among all patients, 22 patients (22 lesions) received surgical treatment, 5 patients (6 lesions) received no surgical treatment because of distant metastasis, and 9 patients (12 lesions) were still in NAC treatment. Among all patients, a total of 27 patients (28 lesions) completed 4 cycles of NAC treatment and were grouped. According to postoperative pathological results and clinical follow-up, NAC treatment was effective in 7 cases and ineffective in 21 cases.

\section{The characteristics of conventional ultrasound, CEUS and $S E$}

\section{Conventional ultrasound findings}

All lesions showed irregular shape. Among all lesions, there were 32 mass types of lesions (32/40, 80.0\%), 39 lesions (39/40, 97.5\%) with unclear boundaries, 38 lesions (38/40, $95.0 \%)$ with heterogeneous echo texture, 24 lesions (24/40, $60.0 \%$ ) with calcification (20 lesions with microcalcification, 4 lesions with micro-and-macro calcification), 3 lesions $(3 / 40,7.5 \%)$ with cystic changes, and 31 lesions $(31 / 40,77.5 \%)$ with hyperechoic halo. Aspect ratio of 34 lesions (34/40, $85.0 \%$ ) was less than or equal to 1 . There were 9 lesions $(9 / 40,22.5 \%)$ invaded the skin, 11 lesions $(11 / 40,27.5 \%)$ invaded the muscle, and 9 lesions $(9 / 40$, $22.5 \%)$ invaded the nipples. Blood flow grade was mainly $2-3$, including 4 lesions $(4 / 40,10.0 \%)$ of grade 2 and 36 lesions $(36 / 40,90.0 \%)$ of grade 3 . The mean values of TD, APD and ULD were $3.86 \pm 1.79,2.27 \pm 0.86$ and $3.26 \pm 1.49 \mathrm{~cm}$ respectively. The maximum cross section area of the tumor was $5.65 \pm 3.26 \mathrm{~cm}^{2}$, and the maximum cross section circumference was $11.07 \pm 4.46 \mathrm{~cm}$.

\section{CEUS findings}

CEUS images of the lesions were all highly enhanced (compared with surrounding normal tissues). Among all lesions, 39 lesions (39/40, 97.5\%) was "fast in" and "slow out", 35 lesions $(35 / 40,87.5 \%)$ presented uneven enhancement, and 11 lesions $(11 / 40,27.5 \%)$ had no, low or equal area of enhancement, including 5 lesions $(5 / 40$, $12.5 \%)$ with no enhancement. There were 21 lesions $(21 / 40$, $52.5 \%)$ with unclear boundary, 30 lesions (30/40, 75.0\%) with irregular shape, 25 lesions $(25 / 40,62.5 \%)$ with "solar sign”, 10 lesions $(10 / 40,25.0 \%)$ with skin invasion, 26 
Table 1 Comparison of conventional ultrasonic characteristics between effective group and ineffective group

\begin{tabular}{|c|c|c|c|}
\hline Features & $\begin{array}{l}\text { Effective } \\
\text { group }(n=7)\end{array}$ & $\begin{array}{c}\text { Ineffective } \\
\text { group }(n=21)\end{array}$ & $P$ \\
\hline Type of lesions & & & 0.633 \\
\hline Mass type & 6 & 17 & \\
\hline Non-mass type & 1 & 4 & \\
\hline Shape & & & 1.000 \\
\hline Regular & 0 & 1 & \\
\hline Irregular & 7 & 20 & \\
\hline Boundary & & & 1.000 \\
\hline Clear & 0 & 0 & \\
\hline Unclear & 7 & 21 & \\
\hline Echo texture & & & 0.556 \\
\hline Homogeneous & 0 & 2 & \\
\hline Heterogeneous & 7 & 19 & \\
\hline Calcification & & & 0.469 \\
\hline Microcalcification & 2 & 11 & \\
\hline $\begin{array}{l}\text { Micro-and-macro } \\
\text { calcification }\end{array}$ & 1 & 2 & \\
\hline No-calcification & 4 & 8 & \\
\hline Cystic change & & & 1.000 \\
\hline Yes & 1 & 2 & \\
\hline No & 6 & 19 & \\
\hline $\begin{array}{l}\text { Peripheral } \\
\text { hyperechoic halo }\end{array}$ & & & 0.646 \\
\hline Yes & 4 & 15 & \\
\hline No & 3 & 6 & \\
\hline Aspect ratio & & & 1.000 \\
\hline$>1$ & 1 & 4 & \\
\hline$\leq 1$ & 6 & 17 & \\
\hline Posterior echo & & & 0.371 \\
\hline Enhancement & 0 & 6 & \\
\hline Attenuation & 2 & 4 & \\
\hline No change & 5 & 11 & \\
\hline Invasion of skin & & & 1.000 \\
\hline Yes & 1 & 5 & \\
\hline No & 6 & 16 & \\
\hline
\end{tabular}

Table 1 (Continued)
Table 1 (Continued)

\begin{tabular}{|c|c|c|c|}
\hline Features & $\begin{array}{c}\text { Effective } \\
\text { group }(n=7)\end{array}$ & $\begin{array}{c}\text { Ineffective } \\
\text { group }(n=21)\end{array}$ & $\mathrm{P}$ \\
\hline Invasion of muscle & & & 0.633 \\
\hline Yes & 1 & 7 & \\
\hline No & 6 & 14 & \\
\hline Invasion of nipples & & & 0.622 \\
\hline Yes & 2 & 4 & \\
\hline No & 5 & 17 & \\
\hline Blood flow classification & & & 0.444 \\
\hline 2 & 1 & 1 & \\
\hline 3 & 6 & 20 & \\
\hline $\mathrm{RI}$ & $0.71 \pm 0.06$ & $0.73 \pm 0.10$ & 0.599 \\
\hline \multicolumn{4}{|l|}{$\begin{array}{l}\text { The largest cross } \\
\text { section }(\mathrm{cm})\end{array}$} \\
\hline TD & $3.13 \pm 1.61$ & $3.83 \pm 2.01$ & 0.417 \\
\hline APD & $1.64 \pm 0.54$ & $2.29 \pm 0.87$ & 0.080 \\
\hline ULD & $2.59 \pm 1.27$ & $3.24 \pm 1.75$ & 0.376 \\
\hline Maximum area $\left(\mathrm{cm}^{2}\right)$ & $4.06 \pm 3.01$ & $5.20 \pm 2.89$ & 0.379 \\
\hline $\begin{array}{l}\text { Maximum } \\
\text { circumference }(\mathrm{cm})\end{array}$ & $8.98 \pm 4.37$ & $10.48 \pm 4.19$ & 0.423 \\
\hline
\end{tabular}

$\mathrm{RI}$, resistance index; TD, transverse diameter $(\mathrm{cm})$; APD, anteroposterior diameter (cm); ULD, upper and lower diameter (cm).

lesions $(26 / 40,65.0 \%)$ with muscle (ectopectoralis) invasion, and 9 lesions $(9 / 40,22.5 \%)$ with nipples invasion. Among the CEUS related parameters, the average value of AT was $9.46 \pm 4.40 \mathrm{~s}$, the average value of TTP was $18.40 \pm 5.09 \mathrm{~s}$, the average value of PI was $23.35 \pm 4.02 \mathrm{~dB}$, the average value of $\mathrm{k}$ was $3.11 \pm 1.61$, and the average value of AUC was $2,048.00 \pm 457.00$.

\section{SE findings}

The mean value of visual lesions elastic imaging score was $4.28 \pm 0.67$, the mean value of maximum strain rate ratio (E1) was $4.88 \pm 0.54$, the mean value of $\mathrm{E} 2$ was $0.96 \pm 0.15$, the mean value of $\mathrm{E} 1 / \mathrm{E} 2$ was $5.23 \pm 1.05$, and the mean value of Em was $4.14 \pm 0.72$.

There was no significant difference between effective and ineffective groups in the characteristics of conventional ultrasound, CEUS and SE $(\mathrm{P}>0.05)$ (Tables 1-4). There was a correlation between whether there were "solar sign" 
Table 2 Comparison of CEUS characteristics between effective group and ineffective group

\begin{tabular}{|c|c|c|c|}
\hline Features & $\begin{array}{l}\text { Effective group } \\
\qquad(\mathrm{n}=7)\end{array}$ & $\begin{array}{c}\text { Ineffective } \\
\text { group }(n=21)\end{array}$ & $P$ \\
\hline Texture of enhancement & & & 1.000 \\
\hline Homogeneous & 1 & 2 & \\
\hline Heterogeneous & 6 & 19 & \\
\hline $\begin{array}{l}\text { Equal or low } \\
\text { enhanced area inside }\end{array}$ & & & 0.545 \\
\hline Yes & 0 & 4 & \\
\hline No & 7 & 17 & \\
\hline Boundary & & & 0.385 \\
\hline Clear & 2 & 12 & \\
\hline Unclear & 5 & 9 & \\
\hline Shape & & & 1.000 \\
\hline Regular & 2 & 6 & \\
\hline Irregular & 5 & 15 & \\
\hline Solar sign & & & 1.000 \\
\hline Yes & 4 & 10 & \\
\hline No & 3 & 11 & \\
\hline Invasion of skin & & & 1.000 \\
\hline Yes & 2 & 5 & \\
\hline No & 5 & 16 & \\
\hline Invasion of muscle & & & 0.674 \\
\hline Yes & 3 & 7 & \\
\hline No & 4 & 14 & \\
\hline Invasion of nipples & & & 1.000 \\
\hline Yes & 1 & 4 & \\
\hline No & 6 & 17 & \\
\hline \multicolumn{4}{|l|}{$\begin{array}{l}\text { The largest cross } \\
\text { section of the lesions } \\
\text { in CEUS }(\mathrm{cm})\end{array}$} \\
\hline TD & $4.11 \pm 1.90$ & $4.34 \pm 1.89$ & 0.780 \\
\hline APD & $2.13 \pm 0.78$ & $2.75 \pm 1.05$ & 0.168 \\
\hline $\begin{array}{l}\text { Maximum area in } \\
\text { CEUS }\left(\mathrm{cm}^{2}\right)\end{array}$ & $6.46 \pm 4.29$ & $7.49 \pm 3.86$ & 0.557 \\
\hline $\begin{array}{l}\text { Maximum circumference } \\
\text { in CEUS }(\mathrm{cm})\end{array}$ & $11.98 \pm 5.54$ & $12.26 \pm 4.80$ & 0.898 \\
\hline
\end{tabular}

CEUS, contrast-enhanced ultrasonography; TD, transverse diameter (cm); APD, anteroposterior diameter (cm).
Table 3 Comparison of CEUS parameters between effective group and ineffective group

\begin{tabular}{lccc}
\hline Parameters & $\begin{array}{c}\text { Effective group } \\
(\mathrm{n}=7)\end{array}$ & $\begin{array}{c}\text { Ineffective group } \\
(\mathrm{n}=21)\end{array}$ & $\mathrm{P}$ \\
\hline AT & $8.42 \pm 3.15$ & $10 \pm 4.85$ & 0.432 \\
TTP & $16.86 \pm 3.63$ & $19.24 \pm 5.70$ & 0.312 \\
PI & $21.57 \pm 3.69$ & $24.29 \pm 4.31$ & 0.149 \\
k & $3.17 \pm 1.65$ & $3.22 \pm 1.68$ & 0.948 \\
AUC & $1,818.391 \pm 453.35$ & $2,007.992 \pm 446.60$ & 0.341 \\
\hline CEUS, contrast-enhanced ultrasonography; AT, arrive time, s; \\
TTP, time to peak, s; PI, peak intensity, dB; k, arrival-peak slope; \\
AUC, area under curve.
\end{tabular}

in CEUS and postoperative pathological grading, and the contingency coefficient was $0.564(\mathrm{P}<0.05)$ (Table 5). The pathological grading of patients without solar sign was higher, which indicated that the effect of NAC was better. The other characteristics of conventional ultrasound, CEUS and SE had no correlation with postoperative pathological grading (Tables $5-8)$.

\section{Discussion}

CEUS and SE, as the new ultrasound technologies, have been used in the diagnosis and treatment evaluation of various organs diseases. However, only some literatures have reported the using in benign and malignant diagnosis of breast lesions, and the clinical applications of them are still rare (13,18-21). In current studies, malignant breast tumors were heterogeneous high enhancement, unclear boundary in CEUS, and the enhancement area was larger than that of conventional ultrasound. However, there was no consensus on the enhancement pattern. Some papers showed that its enhancement mode was "fast in and fast out", while some literatures still showed that its enhancement mode was "fast in and slow out", which was consistent with our study (22-25). The elastography hardness value of breast cancer was larger than that of benign tumor. Some literatures showed that its maximum hardness had certain guiding significance for the identification of benign and malignant lesions, but there was no unified threshold value and diagnostic criteria (24). The characteristics of images are related to the pathological type and the internal components of lesions. It is helpful to understand the internal composition and peripheral infiltration. It provides help for clinical diagnosis and treatment. 
Table 4 Comparison of SE parameters between effective group and ineffective group

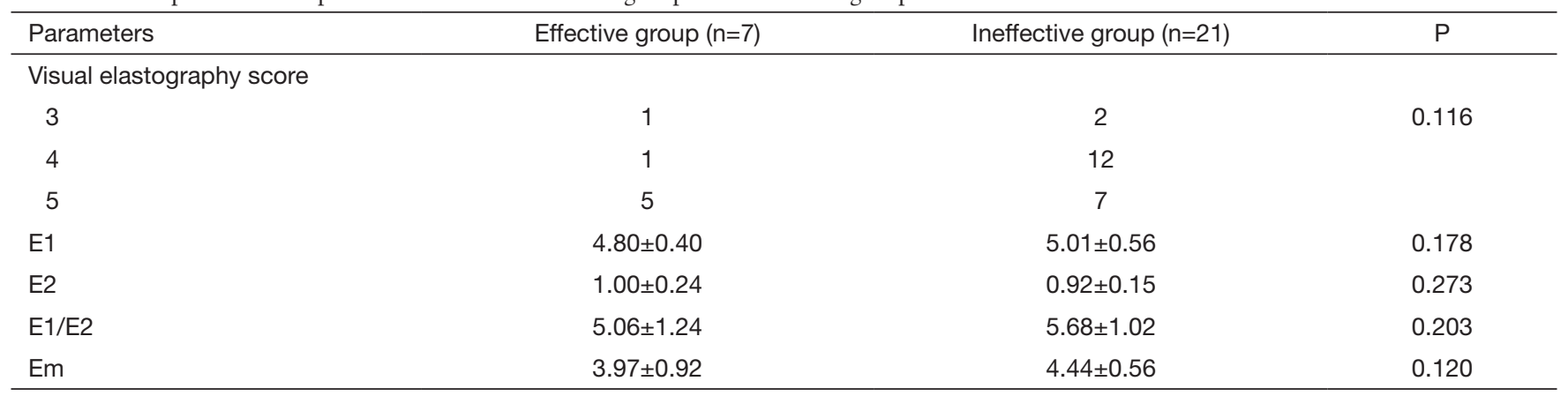

SE, strain elastography; E1, mean maximum strain rate of the lesions; E2, mean strain rate of normal tissues at the same level; Em, mean strain rate of the whole lesion.

Table 5 Correlation analysis between CEUS characteristics and pathological grading

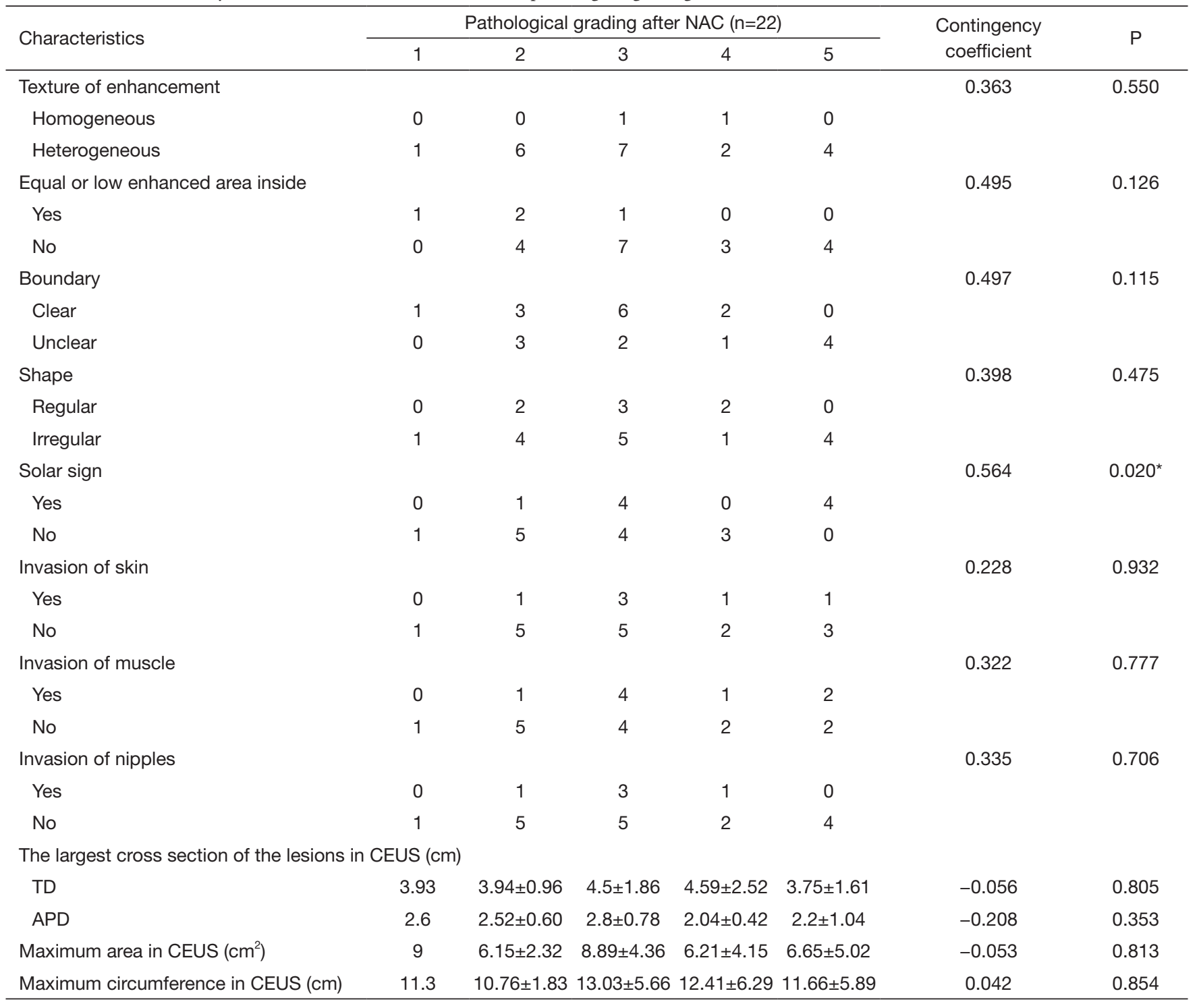

CEUS, contrast-enhanced ultrasonography; NAC, neoadjuvant chemotherapy; TD, transverse diameter (cm); APD, anteroposterior diameter (cm).

(C) Journal of Thoracic Disease. All rights reserved. 
Table 6 Correlation analysis between conventional ultrasonic characteristics and pathological grading

\begin{tabular}{|c|c|c|c|c|c|c|c|}
\hline Features & \multicolumn{5}{|c|}{ Pathological grading after NAC $(n=22)$} & $\begin{array}{c}\text { Contingency } \\
\text { coefficient }\end{array}$ & $\mathrm{P}$ \\
\hline Type of lesions & & & & & & 0.277 & 0.829 \\
\hline Mass type & 1 & 5 & 6 & 2 & 4 & & \\
\hline Non-mass type & 0 & 1 & 2 & 1 & 0 & & \\
\hline Regular & 0 & 1 & 0 & 0 & 0 & & \\
\hline Irregular & 1 & 5 & 8 & 3 & 4 & & \\
\hline Echo texture & & & & & & 0.336 & 0.636 \\
\hline Homogeneous & 0 & 1 & 0 & 0 & 0 & & \\
\hline Microcalcification & 1 & 2 & 6 & 2 & 0 & & \\
\hline Micro-and-macro calcification & 0 & 1 & 0 & 0 & 1 & & \\
\hline No-calcification & 0 & 3 & 2 & 1 & 3 & & \\
\hline Cystic change & & & & & & 0.521 & 0.156 \\
\hline Yes & 1 & 0 & 1 & 0 & 1 & & \\
\hline No & 0 & 6 & 7 & 3 & 3 & & \\
\hline Peripheral hyperechoic halo & & & & & & 0.373 & 0.569 \\
\hline Yes & 0 & 5 & 6 & 2 & 2 & & \\
\hline Enhancement & 0 & 1 & 3 & 0 & 0 & & \\
\hline Attenuation & 0 & 2 & 2 & 0 & 2 & & \\
\hline No change & 1 & 3 & 3 & 3 & 2 & & \\
\hline Invasion of skin & & & & & & 0.335 & 0.706 \\
\hline Yes & 0 & 1 & 3 & 1 & 0 & & \\
\hline No & 1 & 5 & 5 & 2 & 4 & & \\
\hline Invasion of muscle & & & & & & 0.406 & 0.440 \\
\hline Yes & 0 & 1 & 4 & 1 & 0 & & \\
\hline No & 1 & 5 & 4 & 2 & 4 & & \\
\hline Invasion of nipples & & & & & & 0.228 & 0.932 \\
\hline Yes & 0 & 1 & 3 & 1 & 1 & & \\
\hline No & 1 & 5 & 5 & 2 & 3 & & \\
\hline
\end{tabular}

Table 6 (Continued) 
Table 6 (Continued)

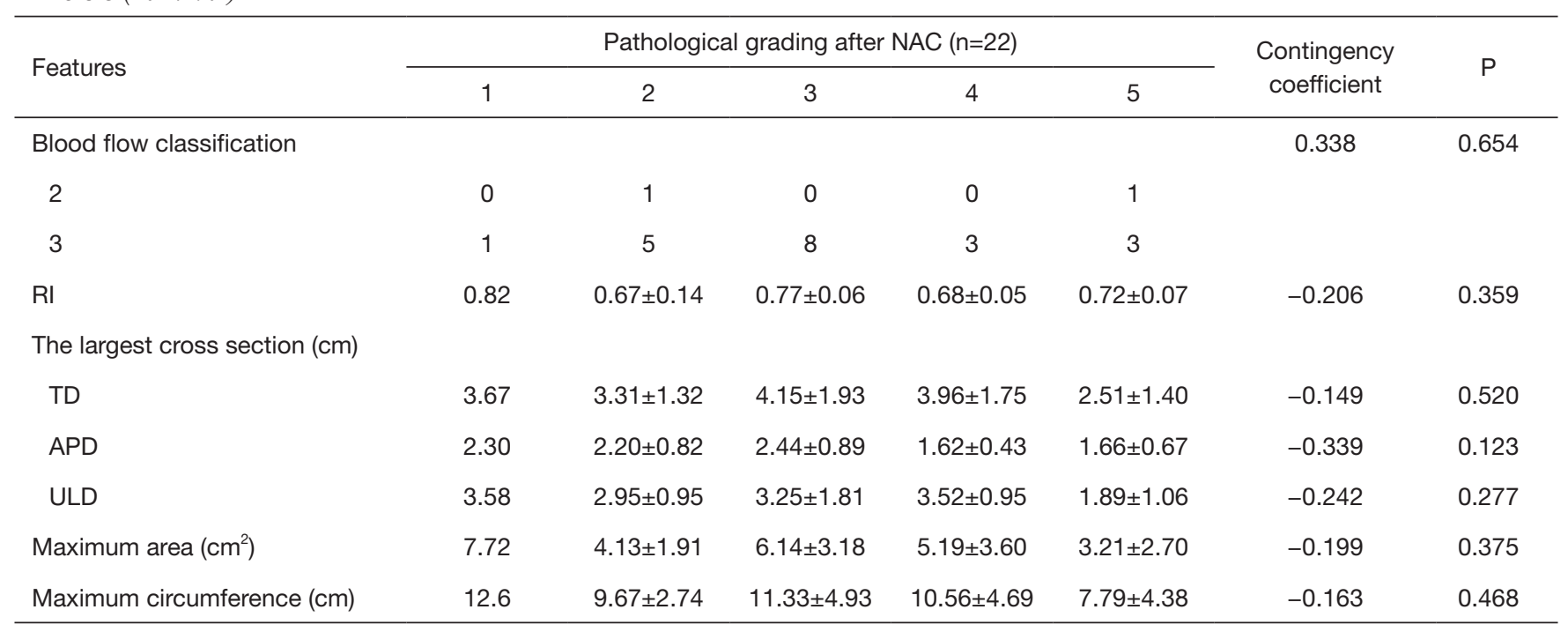

NAC, neoadjuvant chemotherapy; RI, resistance index; TD, transverse diameter (cm); APD, anteroposterior diameter (cm); ULD, upper and lower diameter $(\mathrm{cm})$.

Table 7 Correlation analysis between CEUS parameters and pathological grading

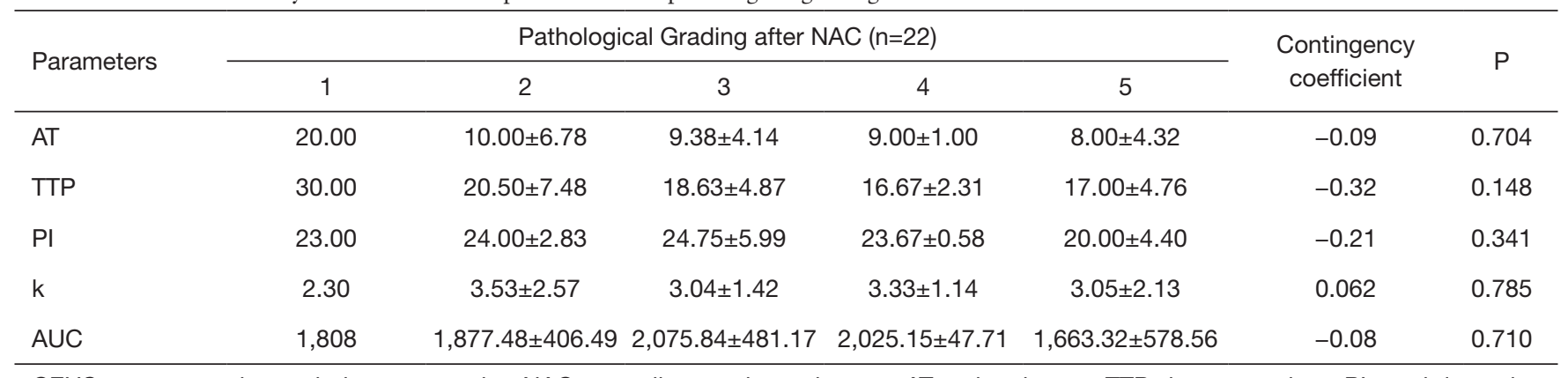

CEUS, contrast-enhanced ultrasonography; NAC, neoadjuvant chemotherapy; AT, arrive time, s; TTP, time to peak, s; PI, peak intensity, $\mathrm{dB}$; k, arrival-peak slope; AUC, area under curve.

Table 8 Correlation analysis between SE parameters and pathological grading

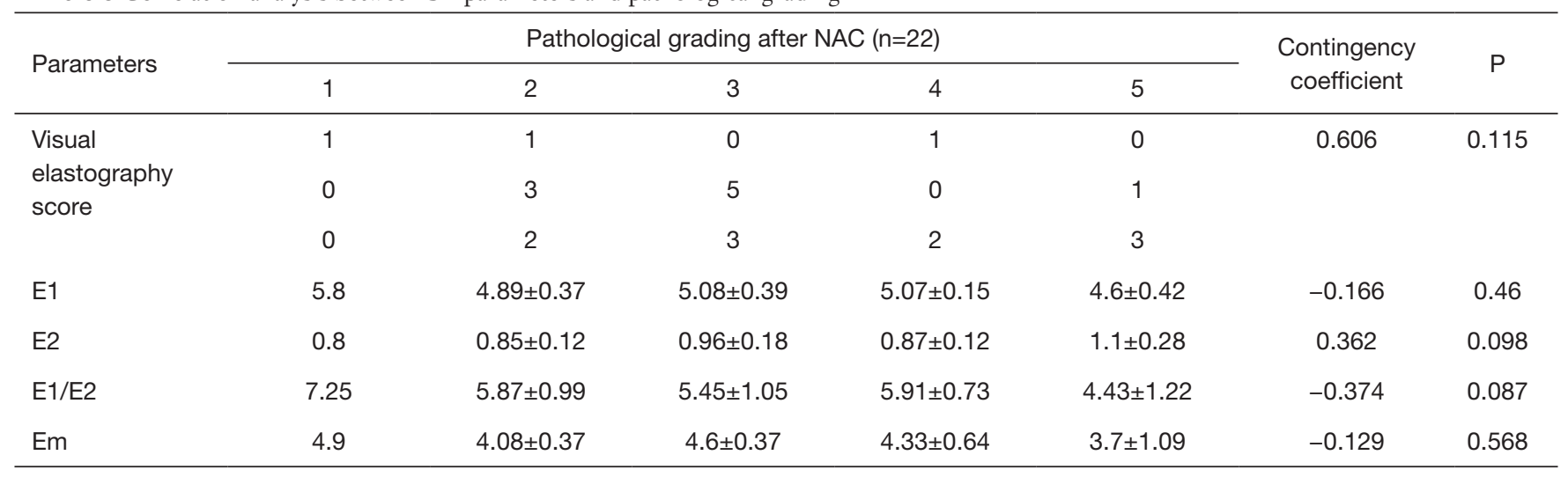

SE, strain elastography; NAC, neoadjuvant chemotherapy; E1, mean maximum strain rate of the lesions; E2, mean strain rate of normal tissues at the same level; Em, mean strain rate of the whole lesion. 

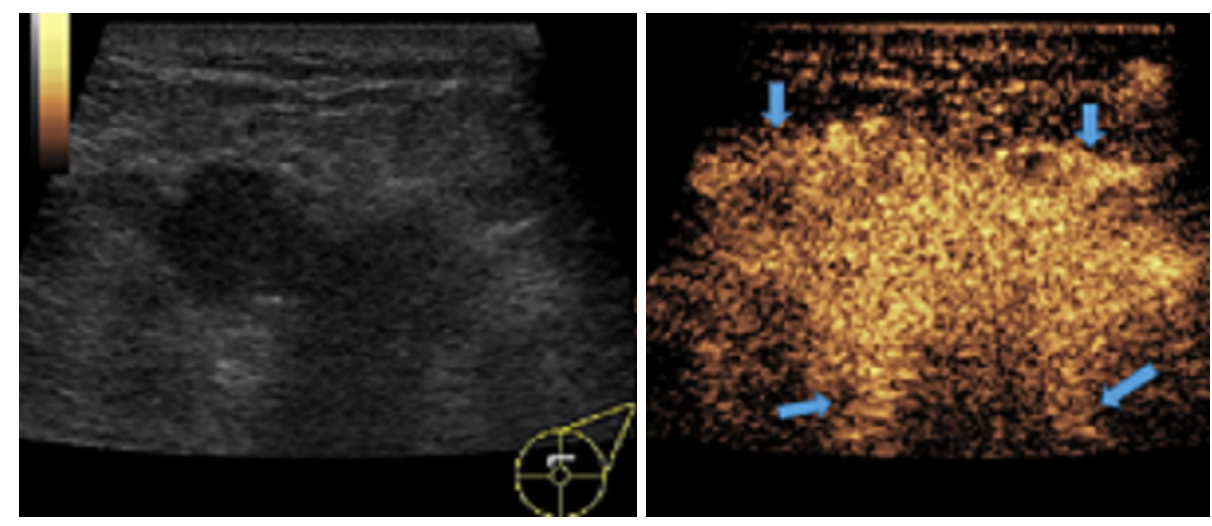

Figure 1 One case of locally advanced invasive ductal carcinoma with CEUS "solar sign". Female, 42 years old, left breast had mass for 1 month. This was a double contrast image of CEUS. The lesion presented high enhancement, and the area of lesion was significantly larger than that of conventional ultrasound. The boundary was not clear, and the blood vessels showed "solar sign". CEUS, contrast-enhanced ultrasonography.

Most of cases in this study were locally advanced invasive ductal carcinoma (38/40, 95\%). Most of the conventional ultrasound findings were unclear boundary, irregularly shaped and hypoechoic masses. Part of the lesions also presented non-mass type $(8 / 40,20 \%)$, with less specific morphology. The lesions only presented as multiple dots of strong echo or local echo disturbance with rich blood flow signals ( $2-3$ grade). Such lesions have also been reported in the article of Girometti et al., 2018 (26). Meanwhile, the aspect ratio was $\leq 1$ in most lesions (34/40, 85.0\%). Analysis showed that the tumor size of LABC was large and growing fast. With the expansion of tumor, the pressure inside the tumor increased. Due to the limitation of anterior and posterior the fascia, the tumor tended to grow towards the area with less peripheral pressure. The lateral growth appeared.

In this study, CEUS of LABC showed high enhancement, and its internal and peripheral blood vessels showed "solar sign" (Figure 1). Relevant studies showed (25) that angiogenic factors could stimulate the breast tissue to produce new blood vessels that extend into the tumor in malignant tumors. And then it would form a network of blood vessels that changed with the growth and necrosis of the tumor. Due to the anisotropy of malignant tumor growth, its internal vascular path was messy, twisted and variable. The characteristic of "solar sign" was often seen as an important indicator for the diagnosis of benign and malignant tumors $(23,25)$. In this study, the tumors of invasive ductal carcinoma all presented as "fast in and slow out". Analysis suggested that there might be abundant arterial regeneration in the tumor. They were rapidly enhanced. Related studies showed that malignant tumors were composed of abnormal blood vessels with increased tortuosity. It tended to increase flow resistance. At the same time, hypoxia and acidosis decreased red blood cell fluidity. They could also lead to venous insufficiency, poor reflux, and thrombosis, which leaded to form a slow withdrawal (27-29). Some study revealed that breast cancer presented as "fast in and fast out". It might be because of the formation of arteriovenous fistula inside the tumor. However, Wan et al. [2012] (25) showed that the enhancement mode could also be "fast in and slow out" in benign tumors. It might be related to the blood supply characteristics of the breast tumor. So the mode of enhancement cannot be used as a distinguishing feature of benign and malignant breast tumors. In addition, in this study, 11 lesions (11/40, $27.5 \%)$ had no, equal or low enhancement areas, including 5 lesions $(5 / 40,12.5 \%)$ had no continuous enhancement areas. In 3 of the 5 lesions, the internal cystic area was found in conventional ultrasound, but the area of no enhancement in CEUS was significantly larger than that in conventional ultrasound. In 2 lesions, no cystic area was found in conventional ultrasound, but CEUS showed nonliquefaction necrosis area without enhancement (Figure 2). In addition, for non-mass breast cancer, it was difficult to be presented in conventional ultrasound. CEUS could show relatively clear boundaries. In particular, CEUS could clearly show the area of lesions and internal vascular conditions, assisting in diagnosis and guiding the area of puncture biopsy (Figures 3,4). Therefore, CEUS was more 
A
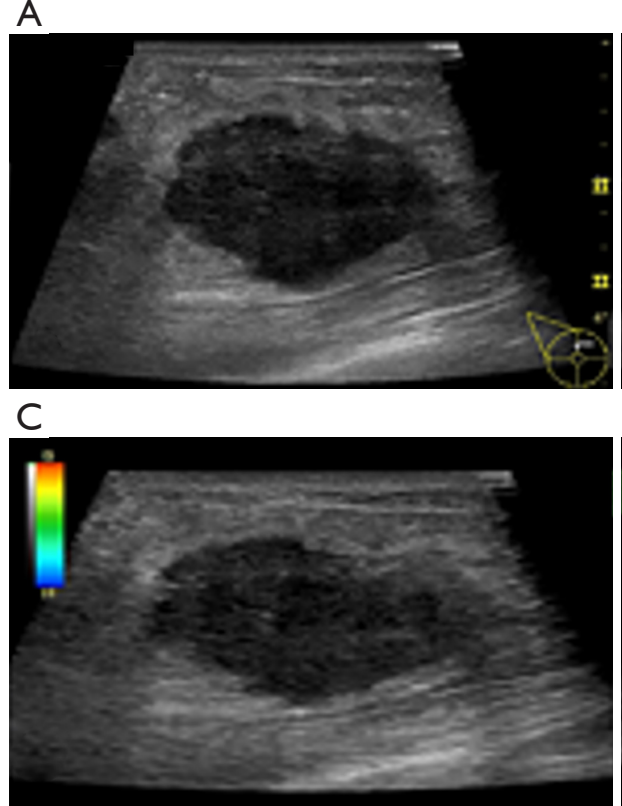

$\mathrm{D}$

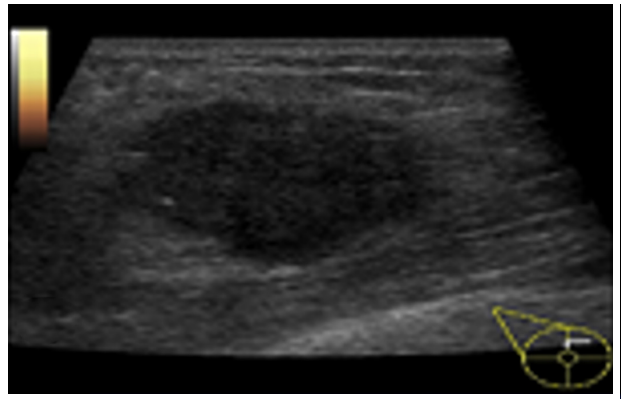

B
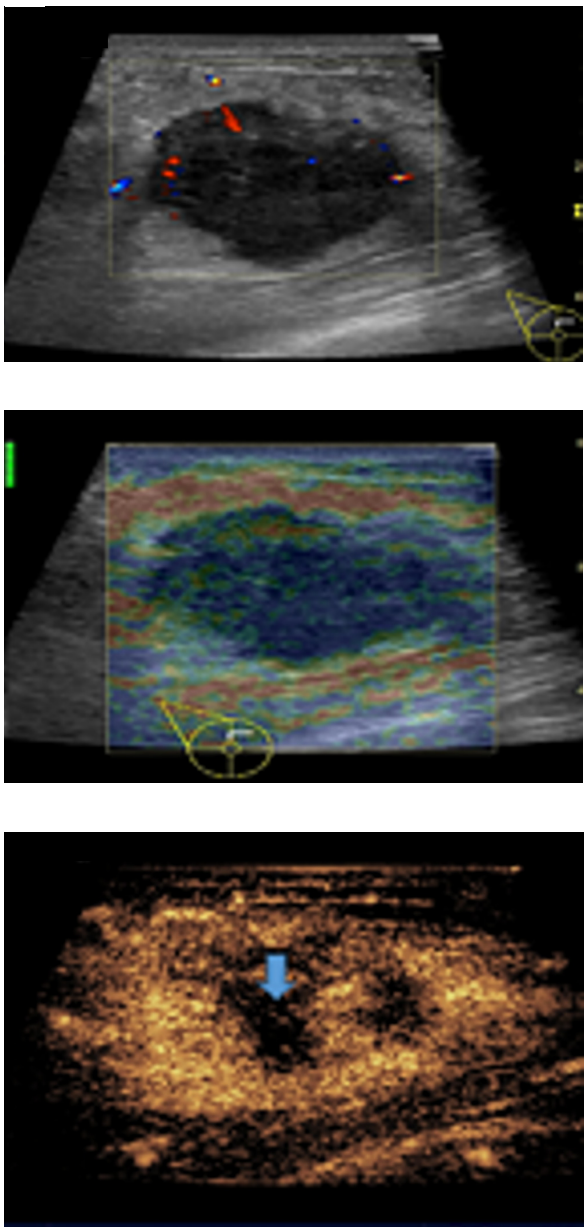

$\mathrm{E}$
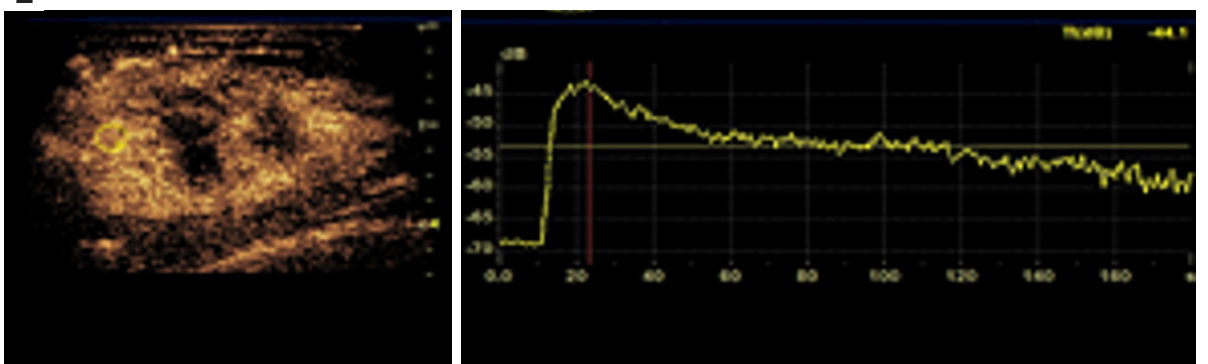

Figure 2 The features of conventional ultrasound, SE and CEUS (mass type) of locally advanced invasive ductal carcinoma in 1 case. Female, 39 years old, the right breast was touched the mass. (A) Conventional ultrasound showed irregular hypoechoic mass in the upper quadrant of the right breast with heterogeneous internal echo, and the aspect ratio was less than 1; (B) multiple short striped blood flow signals can be seen in CDFI, and the blood flow grade was II; (C) SE score was 4, which was relatively hard; (D) under the CEUS mode, the tumor presented heterogeneous and high enhancement with main blood vessels both extending into the tumor and around the periphery. The enhancement area was larger than that of conventional ultrasound. The arrow indicated area was no enhancement; (E) the TIC curve of CEUS showed that enhancement mode of lesion was "fast in and slow out". CEUS, contrast-enhanced ultrasonography; CDFI, color Doppler flow imaging; SE, strain elastography; TIC, time-intensity curve. 
A

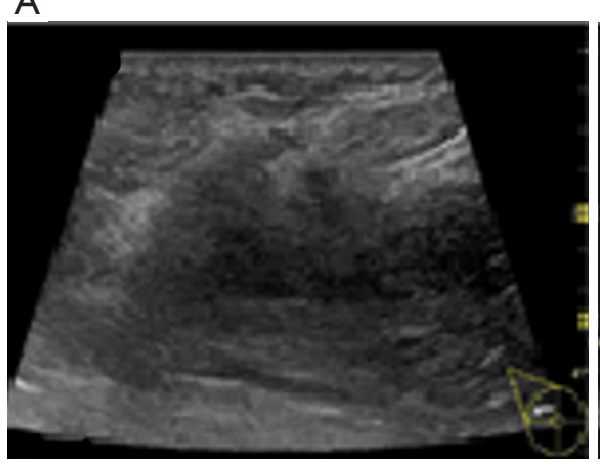

C

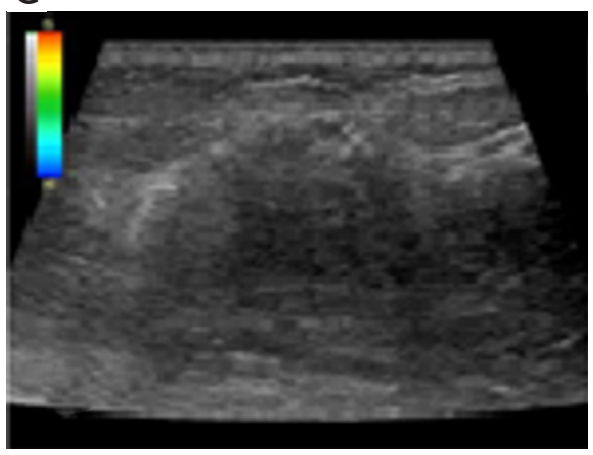

D

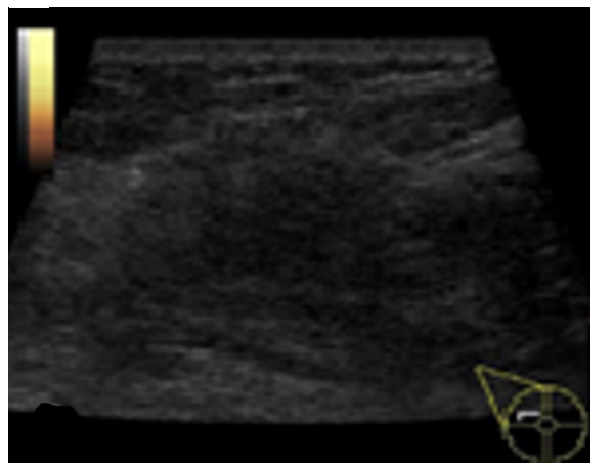

B
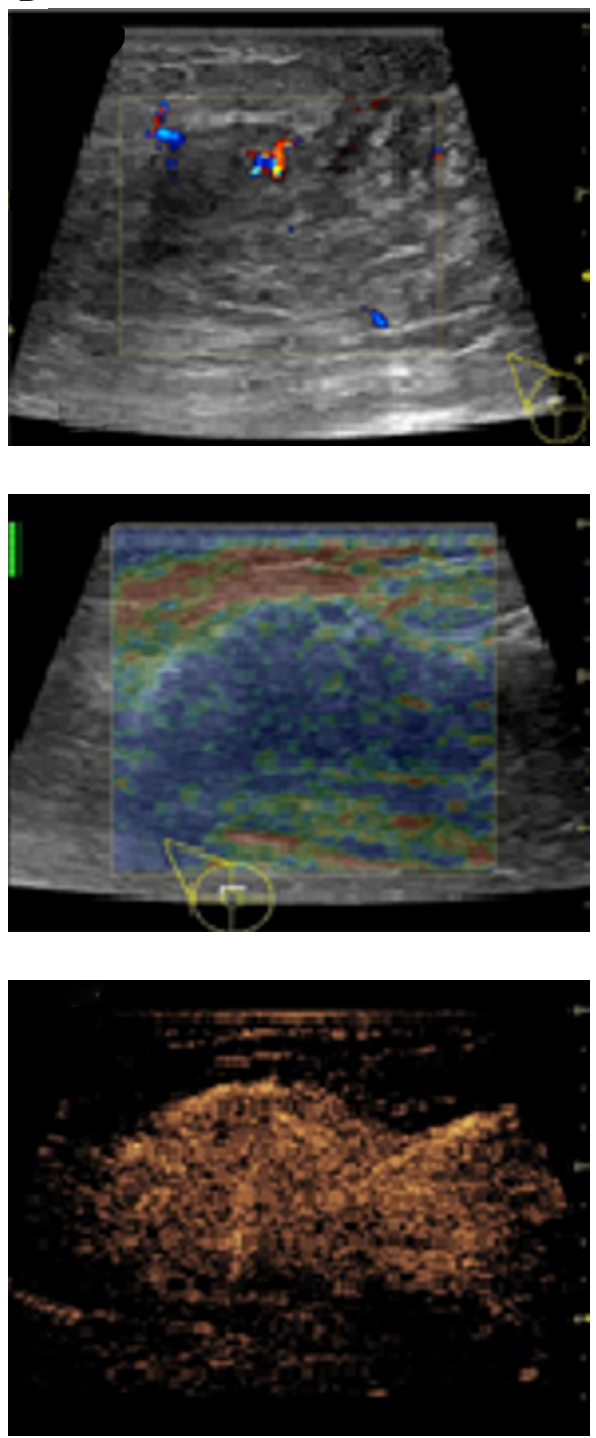

Figure 3 The features of conventional ultrasound, SE and CEUS (non-mass type) of locally advanced invasive ductal carcinoma in 1 case. Female, 34 years old, right breast had mass for 2 months. (A) Conventional ultrasonography showed the disturbance echo in external superior quadrant of right breast external superior quadrant, no specific boundary was observed; (B) multiple striped blood flow signals was seen in CDFI, some of which formed a net. The blood flow rating was grade 3; (C) SE clearly showed the overall area and boundary of lesion. It was 4 points; (D) CEUS showed high enhancement with clear boundaries. CEUS, contrast-enhanced ultrasonography; CDFI, color Doppler flow imaging; SE, strain elastography.

likely to detect muscle or skin infiltration than conventional ultrasound, providing a reference for accurate clinical $\mathrm{T}$ staging of LABC.

The average score of $\mathrm{SE}$ in visual examination of lesions was $4.28 \pm 0.67$ points, and 36 lesions $(36 / 40,90 \%)$ scored above 4 points. It indicated that most tumors had relatively hard internal components. The reason was locally middle and late stage tumors produced more abnormal fibrous tissues for interstitial reaction. It leaded to the hardening of tumor texture (30). Moreover, the uneven distribution of hardness inside the tumor might be due to the large size of the malignant tumor and the uneven and disorderly distribution of its internal components, including necrosis, tumor cells and fibrous foci. The areas with more fibrous 

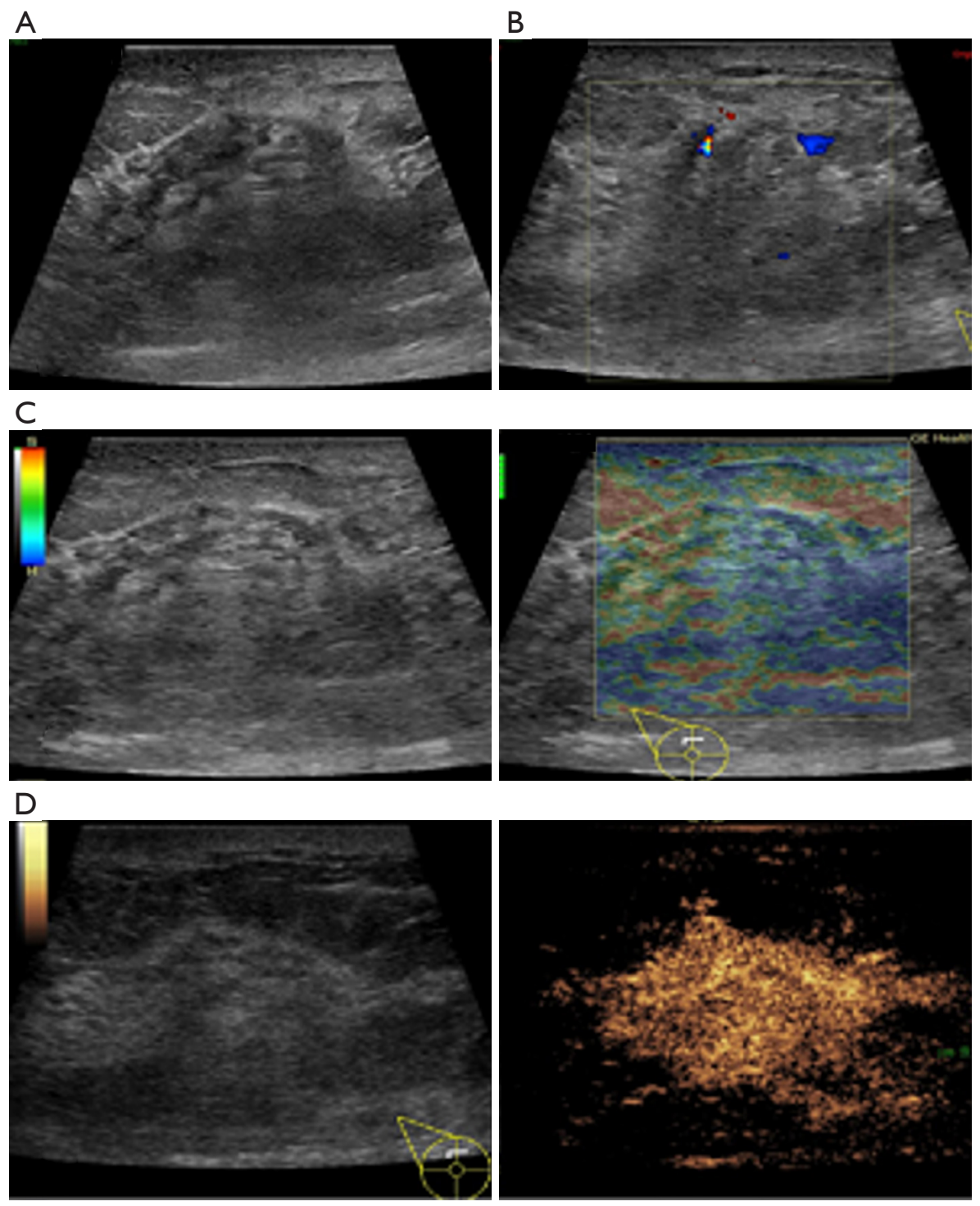

Figure 4 The features of conventional ultrasound, SE and CEUS (non-mass type) of locally advanced invasive ductal carcinoma in 1 case. Female, 54 years old, right breast had mass for 2 months. (A) Conventional ultrasound showed the disturbance in right upper quadrant of breast. No specific boundary was observed; (B) it presented short striped blood flow signal in CDFI. Blood flow was rated grade II; (C) SE showed that the tumor boundary was not clear, and the visual score was 3 points; (D) CEUS showed that the lesions were highly enhanced with clear boundaries and blood vessels showed "solar sign". CEUS, contrast-enhanced ultrasonography; CDFI, color Doppler flow imaging; SE, strain elastography.

components were hard and the areas with more cellular components were soft (Figure 5).

2 cases of invasive micropapillary carcinoma were in stage IIIc. Ipsilateral axillary and supraclavicular lymph node metastasis were found by fine needle puncture. According to WHO classification standards in 2003, invasive micropapillary carcinoma is a subtype of invasive ductal carcinoma of the breast, which can be diagnosed if it contains micropapillary carcinoma in invasive ductal carcinoma. There are papillary tumor cells distributed in the transparent stroma, and tumor nests are usually accompanied by a large number of vascular and lymphocyte infiltration. It has a higher possible of lymphatic metastasis. It is a higher malignant tumor than invasive ductal 

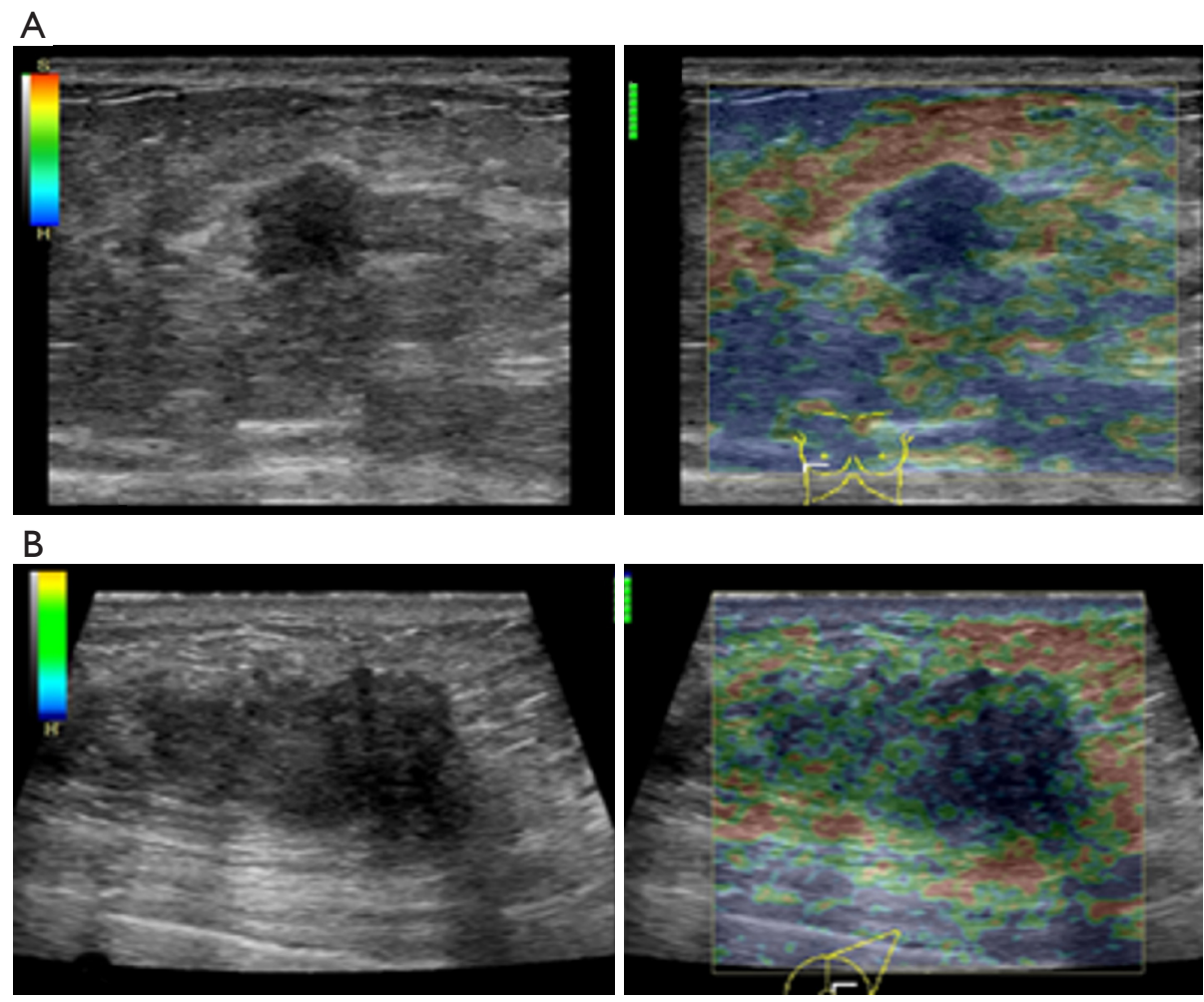

Figure 5 Comparison of elastography in 2 cases with different sizes of locally advanced invasive ductal carcinoma. (A) Female, 59 years old, tumor size was $1.31 \mathrm{~cm} \times 1.25 \mathrm{~cm} \times 1.74 \mathrm{~cm}(\mathrm{TD} \times \mathrm{APD} \times \mathrm{ULD})$ in the right breast. This was a double-contrast image of SE imaging. The elastic distribution in the lesion was relatively uniform. The visual score was 4 points in blue (hard). (B) Female, 44 years old, tumor size was $3.69 \mathrm{~cm} \times 2.16 \mathrm{~cm} \times 3.23 \mathrm{~cm}(\mathrm{TD} \times \mathrm{APD} \times \mathrm{ULD})$ in the left breast. This was a double-contrast image of SE imaging. The distribution of elasticity in the lesion was uneven, showing blue and green (moderate hardness). The visual score is 3 points. TD, transverse diameter (cm); $\mathrm{APD}$, anteroposterior diameter (cm); ULD, upper and lower diameter $(\mathrm{cm})$.

carcinoma (31). However, the conventional ultrasonography and CEUS showed no specific characteristic, which was similar to invasive ductal carcinoma. The diagnosis relied mainly on histopathological examination. In this study, there were only 2 cases of invasive micropapillary carcinoma. The size of the sample needed to be further expanded for the study on the characteristics of CEUS.

Our study showed that it was not ideal to predict the effectiveness of NAC by ultrasonic imaging before NAC treatment. In some literature studies, for NAC treatment of breast cancer, the content of proliferating cells was often associated with the efficacy of NAC (32-34). We focused on the features of LABC, so that only LABC had been included. The pathologic types of included patients were single. It was necessary to study the features of different subtypes in the future. However, there was correlation between the appearance of solar sign and pathological grading. The pathological grading was higher in patients without solar sign, which indicated that the effect of NAC was better. The relevant literatures showed that the reduction of blood vessels during the treatment was an important sign of effectiveness for breast cancer (35). It was consistent with this study. Therefore, blood vessel in tumor was an important indicator of whether NAC treatment was effective. Its value in NAC evaluation needs further study.

\section{Conclusions}

Conventional ultrasound findings of LABC were as follows: irregular shape, unclear boundary, microcalcification, aspect ratio less than or equal to 1 , and low-echo masses with grade 3 blood flow; CEUS features were uneven and high enhancement of "fast in and slow out", and the "solar sign" was often seen. SE showed that the lesions were 
significantly harder than surrounding normal tissues.

CEUS can not only fully display both internal and peripheral vascular distribution of breast cancer, it can also display area of tumor necrosis. Ultrasound imaging before NAC had no relationship with pathological complete response or not. However, "solar sign" in CEUS was an important feature and had correlation with postoperative pathological grading. The pathological grading was higher in the patients without solar sign.

\section{Acknowledgments}

Funding: This work was supported by China postdoctoral science foundation (2017M620683); and PUMC Youth Fund and the Fundamental Research Funds for the Central Universities (2017320015).

\section{Footnote}

Conflicts of Interest: The authors have no conflicts of interest to declare.

Ethical Statement: The authors are accountable for all aspects of the work in ensuring that questions related to the accuracy or integrity of any part of the work are appropriately investigated and resolved. This study was approved by the Institutional Ethics Review Board (National Cancer Center/ National Clinical Research Center for Cancer/Cancer Hospital, Chinese Academy of Medical Sciences and Peking Union Medical College NCC2016 YZ-15). Each patient was consent informed.

\section{References}

1. WHO Guidelines Approved by the Guidelines Review Committee. WHO Position Paper on Mammography Screening. Oncology in Clinical Practice, 2014.

2. Liu XY, Gou ZC, Cao ZG, et al. Surgical management of breast cancer in China: the Fudan University Shanghai Cancer Center experience. Transl Cancer Res 2017;6:588-98.

3. Amin MB, Greene FL, Edge SB, et al. The eighth edition ajcc cancer staging manual: continuing to build a bridge from a population-based to a more "personalized" approach to cancer staging. CA Cancer J Clin 2017;67:93-9.

4. Barton H, Shatti D, Jones CA, et al. Review of radiological screening programmes for breast, lung and pancreatic malignancy. Quant Imaging Med Surg 2018;8:525-34.

5. Ha R, Mema E, Guo X, et al. Quantitative 3D breast magnetic resonance imaging fibroglandular tissue analysis and correlation with qualitative assessments: a feasibility study. Quant Imaging Med Surg 2016;6:144-50.

6. Weber JJ, Jochelson MS, Eaton A, et al. MRI and Prediction of Pathologic Complete Response in the Breast and Axilla after Neoadjuvant Chemotherapy for Breast Cancer. J Am Coll Surg 2017;225:740-6.

7. Luengo-Gil G, Gonzalez-Billalabeitia E, Chaves-Benito A, et al. Effects of conventional neoadjuvant chemotherapy for breast cancer on tumor angiogenesis. Breast Cancer Res Treat 2015;151:577-87.

8. Hidrovo I, Dey J, Chesal ME, et al. Experimental method and statistical analysis to fit tumor growth model using SPECT/CT imaging: a preclinical study. Quant Imaging Med Surg 2017;7:299-309.

9. Amioka A, Masumoto N, Gouda N, et al. Ability of contrast-enhanced ultrasonography to determine clinical responses of breast cancer to neoadjuvant chemotherapy. Jpn J Clin Oncol 2016;46:303-9.

10. Lee SH, Chang JM, Han W, et al. Shear-Wave Elastography for the Detection of Residual Breast Cancer After Neoadjuvant Chemotherapy. Ann Surg Oncol 2015;22:S376-84.

11. Suvannarerg V, Chitchumnong P, Apiwat W, et al. Diagnostic performance of qualitative and quantitative shear wave elastography in differentiating malignant from benign breast masses, and association with the histological prognostic factors. Quant Imaging Med Surg 2019;9:386-98.

12. Carlsen J, Ewertsen C, Sletting S, et al. Ultrasound Elastography in Breast Cancer Diagnosis. Ultraschall Med 2015;36:550-62; quiz 563-5.

13. Zhao YX, Liu S, Hu YB, et al. Diagnostic and prognostic values of contrast-enhanced ultrasound in breast cancer: a retrospective study. Onco Targets Ther 2017;10:1123-9.

14. Adler DD, Carson PL, Rubin JM, et al. Doppler ultrasound color flow imaging in the study of breast cancer: preliminary findings. Ultrasound Med Biol 1990;16:553-9.

15. Itoh A, Ueno E, Tohno E, et al. Breast disease: clinical application of US elastography for diagnosis. Radiology 2006;239:341-50.

16. Amin MB, Edge S, Greene FL, et al. AJCC Cancer Staging Manual 8th ed. New York: Springer, 2016.

17. Ogston KN, Miller D, Payne S, et al. A new histological grading system to assess response of breast cancers to 
primary chemotherapy: prognostic significance and survival. Breast 2003;12:320-7.

18. Pang EHT, Chan A, Ho SG, et al. Contrast-Enhanced Ultrasound of the Liver: Optimizing Technique and Clinical Applications. AJR Am J Roentgenol 2018;210:320-32.

19. Sidhu PS, Cantisani V, Dietrich CF, et al. The EFSUMB Guidelines and Recommendations for the Clinical Practice of Contrast-Enhanced Ultrasound (CEUS) in Non-Hepatic Applications: Update 2017 (Long Version). Ultraschall Med 2018;39:e2-44.

20. Dietrich CF, Averkiou M, Nielsen MB, et al. How to perform Contrast-Enhanced Ultrasound (CEUS). Ultrasound Int Open 2018;4:E2-15.

21. EFSUMB Guidelines and Recommendations on the Clinical Use of Liver Ultrasound Elastography, 2017.

22. Leng $X$, Huang G, Ma F, et al. Regional ContrastEnhanced Ultrasonography (CEUS) Characteristics of Breast Cancer and Correlation with Microvessel Density (MVD). Med Sci Monit 2017;23:3428-36.

23. Xiang LH, Yao MH, Xu G, et al. Diagnostic value of contrast-enhanced ultrasound and shear-wave elastography for breast lesions of sub-centimeter. Clin Hemorheol Microcirc 2017;67:69-80.

24. Hu Q, Wang XY, Zhu SY, et al. Meta-analysis of contrastenhanced ultrasound for the differentiation of benign and malignant breast lesions. Acta Radiologica 2015;56:25-33.

25. Wan C, Du J, Fang H, et al. Evaluation of breast lesions by contrast enhanced ultrasound: qualitative and quantitative analysis. Eur J Radiol 2012;81:e444-50.

26. Girometti R, Zanotel M, Londero V, et al. Automated breast volume scanner (ABVS) in assessing breast cancer

Cite this article as: Gu LS, Zhang R, Wang Y, Liu XM, Ma F, Wang JY, Sun XY, Liu MJ, Wang B, Zou SM. Characteristics of contrast-enhanced ultrasonography and strain elastography of locally advanced breast cancer. J Thorac Dis 2019;11(12):52745289. doi: $10.21037 /$ jtd.2019.11.52 size: A comparison with conventional ultrasound and magnetic resonance imaging. Eur Radiol 2018;28:1000-8.

27. Dewhirst MW, Secomb TW. Transport of drugs from blood vessels to tumour tissue. Nat Rev Cancer 2017;17:738-50.

28. Jain RK. Normalization of tumor vasculature: an emerging concept in antiangiogenic therapy. Science 2005;307:58-62.

29. Winkler F, Kozin SV, Tong RT, et al. Kinetics of vascular normalization by VEGFR2 blockade governs brain tumor response to radiation: role of oxygenation, angiopoietin-1, and matrix metalloproteinases. Cancer Cell 2004;6:553-63.

30. Dialani V, Chadashvili T, Slanetz PJ. Role of imaging in neoadjuvant therapy for breast cancer. Ann Surg Oncol 2015;22:1416-24.

31. Tavasseli FA, Devilee P. World Health Organization classification of tumors. Pathology and female gentital organs. Lyon: IARC Press, 2003:35-6.

32. Knutson TP, Lange CA. Tracking progesterone receptormediated actions in breast cancer. Pharmacol Ther 2014;142:114-25.

33. Butler EN, Tse CK, Bell ME, et al. Active smoking and risk of luminal and basal- -like breast cancer subtypes in the Carolina breast cancer study. Cancer Causes Control 2016;27:775-86.

34. Liang C, Cheng Z, Huang Y, et al. An MRI-based Radiomics Classifier for Preoperative Prediction of Ki-67 Status in Breast Cancer. Acad Radiol 2018;25:1111-7.

35. Gu S, Xue J, Xi Y, et al. Evaluating the effect of Avastin on breast cancer angiogenesis using synchrotron radiation. Quant Imaging Med Surg 2019;9:418-26. 